\title{
Van schaduwbankieren en dogmatische bezwaren
}

\author{
Bespreking van het proefschrift van mr.J. Diamant
}

\author{
Prof. mr. drs. M. Haentjens*
}

\section{Inleiding}

Voordat Lehman Brothers insolvent raakte, mochten repurchase agreements, securities lending-overeenkomsten en zekerheidsarrangementen in het kader van derivatencontracten zich in de belangstelling van slechts een handjevol specialisten verheugen. Deze overeenkomsten bleken echter in belangrijke mate te hebben bijgedragen aan de insolventie van Lehman Brothers op 15 september 2008, maar ook aan de problemen van verzekeringsgigant AIG, die gered moest worden door de Amerikaanse overheid voor ruim \$182 miljard. Sindsdien staan zij dan ook volop in de schijnwerpers van juristen en beleidsmakers. Dat zij thans ook wel worden gerekend tot het sinister klinkende 'schaduwbankieren' heeft ongetwijfeld bijgedragen aan hun populariteit. Het hier te bespreken proefschrift, dat deze overeenkomsten tot onderwerp heeft, zou dan ook niet op een beter tijdstip hebben kunnen verschijnen.

Het proefschrift van Jael Diamant, op 21 januari 2015 verdedigd aan Tilburg University, ${ }^{1}$ bespreekt preciezer gezegd hoe de Europese Collateral Richtlijn ${ }^{2}$ de zojuist genoemde overeenkomsten (tezamen in het boek aangeduid als financiëlezekerheidsarrangementen ${ }^{3}$ ) een juridische infrastructuur heeft geboden. Deze richtlijn is reeds in 2002 aangenomen en in het Nederlandse recht hoofdzakelijk geimplementeerd in art.

* Prof. mr. drs. M. Haentjens is hoogleraar financieel recht aan de Universiteit Leiden.

1. J. Diamant, De Collateral Richtlijn (diss. Tilburg), 2015. In voorliggende bespreking zal ik verwijzen naar de handelseditie van dit proefschrift dat is verschenen in de serie Recht en Praktijk - Financieel Recht, Deventer: Wolters Kluwer 2014 .

2. Richtlijn 2002/47/EG van het Europees Parlement en de Raad van 6 juni 2002 betreffende financiëlezekerheidsovereenkomsten, PbEG 2002, L 168/43.

3. Zie over het verschil tussen 'financiëlezekerheidsarrangementen' en 'financiëlezekerheidsovereenkomsten' uitgebreid Diamant 2014, p. 68-74. Aldaar betoogt Diamant dat de term 'financiëlezekerheidsovereenkomst' een obligatoire connotatie heeft, terwijl daarmee (ook) een goederenrechtelijke overeenkomst moet worden bedoeld, zodat de meer goederenrechtelijke term 'financiëlezekerheidsarrangement' te verkiezen valt. Hoewel ik dat betwijfel, zal ik in het hiernavolgende deze terminologie volgen, om aldus aan te sluiten bij het te bespreken proefschrift. Overigens hoeft men het niet met deze stelling eens te zijn om in te zien dat de Collateral Richtlijn beter in Boek 3 BW dan in Boek 7 BW zou zijn geimplementeerd, zoals Diamant ook (terecht) in ditzelfde verband betoogt.
7:51-56 van het Burgerlijk Wetboek (BW). Vermogensrechtelijk is de Collateral Richtlijn van groot belang, omdat de Europese wetgever hiermee het terrein van het goederenrecht heeft betreden (hetgeen uitzonderlijk is) en noviteiten heeft geïntroduceerd in het nationale vermogensrecht van alle in dit proefschrift onderzochte jurisdicties.

\section{Lehman en schaduwbankieren: ontwikkelingen}

Zoals te doen gebruikelijk in verhandelingen over financiëlezekerheidsarrangementen, begint ook Diamant met enige cijfers die de huidige omvang van dit marktsegment weergeven, ${ }^{4}$ kennelijk met het doel het belang van haar onderzoek te benadrukken. Die cijfers zijn inderdaad indrukwekkend en de biljoenen vliegen je om de oren, hetgeen bijna zou doen vergeten hoe de eerdergenoemde repurchase agreements (liefkozend: repos) zeven jaar geleden Lehman Brothers in de afgrond hebben doen storten, en de rest van de wereld welhaast daarbij. ${ }^{5}$

Destijds leende Lehman Brothers door middel van repos $\$ 50$ miljard van andere banken en verstrekte deze crediteuren voor hetzelfde bedrag aan effecten tot zekerheid. ${ }^{6}$ De effecten betroffen deels mortgage-backed securities (door hypotheekrechten gedekte effecten). Toen de waarde van hypotheekrechten door de crisis in de Amerikaanse huizenmarkt kelderde, daalden ook deze effecten in waarde. Terwijl de tot zekerheid overgedragen effecten aldus in waarde daalden, eisten sommige crediteuren een aanvulling van het onderpand, welk extra onderpand Lehman op grond van de repos verplicht was te verstrekken. ${ }^{7}$ Andere crediteuren beëindigden hun repos en gingen geen nieuwe aan. De partijen die de repos beëindigden,

4. Diamant 2014, p. 2-3.

5. Hoewel de moderne variant van de repo in de tweede helft van de vorige eeuw tot ontwikkeling is gekomen, heeft hij oude wortels. Zo bedongen de financiers van de Spaanse kroon aan het einde van de zestiende eeuw dat zij langlopende staatsobligaties verkregen tot zekerheid van terugbetaling van hun leningen. Zie M. Haentjens, De autonomie van de alchemist, Den Haag: Boom Juridische uitgevers 2014, p. 33 en de aldaar gegeven verwijzingen. Ook de hiernavolgende twee alinea's zijn aan deze publicatie ontleend.

6. Chapter 11 Case No. 08-13555 (JMP) in re Lehman Brothers Holdings Inc. et al., Report of Anton R. Valukas, Examiner, p. 6.

7. Zie bijv. art. 4 van de Global Master Repurchase Agreement (2011 version). 
trachtten de tot zekerheid verstrekte effecten te verkopen om zich op de opbrengst daarvan te verhalen. Deze paniekverkoop deed de mortgage-backed securities nog verder in waarde dalen, zodat nog meer partijen extra onderpand eisten, hun repos beëindigden, enzovoort, enzovoort. Dat betekende het einde van Lehman Brothers. ${ }^{8}$

De insolventie van Lehman Brothers wordt vaak beschouwd als het begin van de financiële crisis ${ }^{9}$ en repos kwamen dan ook snel in beeld als een van de oorzaken ervan. Bovendien wordt de repo gezien als schaduwbankieren, dat wil zeggen: als een niet aan direct overheidstoezicht onderworpen en dus als een voor de stabiliteit van het financieel stelsel mogelijk gevaarlijke bancaire activiteit. ${ }^{10}$ Beide redenen hebben organisaties als de Financial Stability Board (FSB) ${ }^{11}$ ertoe gebracht te (doen) onderzoeken of repos niet aan banden zouden moeten worden gelegd. In dezelfde geest riep het Europees Parlement de Europese Commissie in november 2012 op toezichthouders de bevoegdheid te verlenen minimumeisen te stellen aan het tot zekerheid verschafte onderpand. Ook zou moeten worden onderzocht of de beschikkingsbevoegdheid van de crediteur ten aanzien van de hem tot zekerheid overgedragen effecten niet zou moeten worden beperkt. Ten derde zou de positie van de crediteur in het faillissement van de debiteur aan banden moeten worden gelegd. ${ }^{12}$ De FSB kwam tot vergelijkbare, zij het iets genuanceerdere aanbevelingen. ${ }^{13}$

In de Bank Recovery and Resolution Directive ${ }^{14}$ heeft de Europese wetgever reeds een deel van deze aanbevelingen in wetgeving omgezet. Zo bepaalt deze richtlijn, die sinds 26 november 2015 in het Nederlandse recht hoofdzakelijk in deel 3a van de Wet op het financieel toezicht (Wft) is geïm-

8. Zie bijv. European Parliament Report on Shadow Banking (2012/2115(INI)), 20 november 2012, p. 12; P. Paech, Shadow Banking: Legal Issues of Collateral Assets and Insolvency Law, Note to the European Parliament (juni 2013), p. 11 en Vast Market Has Weakness for Withdrawals, Financial Times 5 maart 2013.

9. Zie bijv. FSB, Shadow Banking: Strengthening Oversight and Regulation, 27 oktober 2011, p. 1-2.

10. Zie bijv. FSB 2011; European Parliament Report on Shadow Banking (2012/2115(INI)), 20 november 2012; FSB, Strengthening Oversight and Regulation of Shadow Banking. A Policy Framework for Addressing Shadow Banking Risks in Securities Lending and Repos (18 november 2012); Communication from the Commission to the Council and the European Parliament, Shadow Banking - Addressing New Sources of Risk in the Financial Sector, 4 september 2013, COM(2013)614 final.

11. De FSB is een internationale organisatie die aanbevelingen doet ten aanzien van het wereldwijde financiële systeem. Het werd in april 2009 opgericht naar aanleiding van de G20-top in Londen en is gevestigd in Basel.

12. European Parliament Report on Shadow Banking (2012/2115(INI)).

13. Zie FSB, Strengthening Oversight and Regulation of Shadow Banking. A Policy Framework for Addressing Shadow Banking Risks in Securities Lending and Repos (29 augustus 2013), Recommendations 6-9 en 11.

14. Richtlijn 2014/59/EU van het Europees Parlement en de Raad van 15 mei 2014 betreffende de totstandbrenging van een kader voor het herstel en de afwikkeling van kredietinstellingen en beleggingsondernemingen en tot wijziging van Richtlijn 82/891/EEG van de Raad en de Richtlijnen 2001/24/EG, 2002/47/EG, 2004/25/EG, 2005/56/EG 2007/36/EG, 2011/35/EU, 2012/30/EU en 2013/36/EU en de Verordeningen (EU) 1093/2010 en (EU) 648/2012, van het Europees Parlement en de Raad, PbEU 2014, L 173/190. plementeerd, onder andere dat crediteuren in financiëlezekerheidsarrangementen met een bank als debiteur deze overeenkomsten niet mogen beëindigen op de enkele grond dat, kort gezegd, deze bank/debiteur wordt onderworpen aan een maatregel van overheidsinterventie (art. 3a:57 jo. art. 1:76b Wft). Inmiddels is ook een voorstel voor een 'Verordening van het Europees Parlement en de Raad betreffende de rapportage en de transparantie van effectenfinancieringstransacties' aangenomen, ${ }^{15}$ waarin vooral wordt ingezet op de rapportage van financiëlezekerheidsarrangementen bij een 'transactieregister'. ${ }^{16}$ Door deze rapportage zal de omvang van de risico's die deze overeenkomsten meebrengen ten minste in beeld worden gebracht, zo is de gedachte. Als laatste ontwikkeling kan worden gewezen op het consultatiedocument dat de Basel Committee on Banking Supervision op 5 november 2015 heeft verspreid en waarin wordt voorgesteld, kort gezegd, voor bepaalde soorten financiëlezekerheidsarrangementen minimumeisen te stellen aan het tot zekerheid verschafte onderpand. ${ }^{17}$

\section{Hoofdvraag: harmonisatie geslaagd?}

Het proefschrift van Diamant 'beperkt' zich tot de dogmatische consequenties die de implementatie van de Collateral Richtlijn heeft meegebracht voor het Nederlandse, Engelse, Duitse en Belgische recht, en besteedt helaas geen aandacht aan de zojuist besproken ontwikkelingen. De hoofdvraag die Diamant zich heeft gesteld, is of de Collateral Richtlijn haar doel heeft bereikt, dat wil zeggen: of zij tot geharmoniseerd goederenrecht op het door de richtlijn bestreken terrein heeft geleid. Haar antwoord: dat is slechts ten dele gelukt. Voor zover dat niet is gelukt, kan dat rekenen op afkeuring van Diamant. $\mathrm{Zij}$ zou dan ook de voorkeur hebben gegeven aan een verordening en Diamant is er niet van overtuigd dat een richtlijn een beter instrument is geweest. ${ }^{18}$ Bovendien is zij van mening dat nationale wetgevers 'een steekje hebben laten vallen', waar zij de richtlijn zodanig hebben ingepast in hun nationale recht dat dit tot verschillen tussen de nationale rechtsordes van de onderzochte lidstaten heeft geleid. ${ }^{19}$

15. $\operatorname{COM}(2014) 0040$ - C7-0023/2014 - 2014/0017(COD). Het Europese wetgevingsproces ten aanzien van dit voorstel is op 25 november 2015 afgerond en de definitieve tekst zal binnenkort in het Publicatieblad verschijnen. Voor de laatste parlementaire tekst, zie <www.europarl.europa. eu/sides $/$ getDoc.do? type $=$ TA\&language $=$ EN\&reference $=$ P8-TA-2015$0387>$.

16. Zowel de Collateral Richtlijn als de voorgestelde verordening heeft betrekking op repos en securities lending-overeenkomsten. In de Collateral Richtlijn is echter voor een functionele benadering gekozen en de bepalingen van deze richtlijn kunnen daarom ook andere overeenkomsten betreffen, terwijl de reikwijdte van de voorgestelde verordening met zoveel woorden tot deze (en enige andere, precies omschreven) transacties is beperkt. Zie art. 3 onder 6 voorstel Verordening van het Europees Parlement en de Raad betreffende de rapportage en de transparantie van effectenfinancieringstransacties.

17. Basel Committee on Banking Supervision, Bank for International Settlements, Haircut Floors for Non-centrally Cleared Securities Financing Transactions, consultative document, 5 november 2015, te raadplegen via <www.bis.org/bcbs/publ/d340.pdf>.

18. Diamant 2014, p. 43-45.

19. Diamant 2014, p. 248. 


\section{Maandblad}

Kennelijk huldigt Diamant het standpunt dat harmonisering van groter belang is dan de coherentie van een nationale rechtsorde. Binnen het kader van de gestelde hoofdvraag valt hierop weinig af te dingen, maar het is jammer dat Diamant die hoofdvraag niet ruimer heeft geformuleerd en dit standpunt aan een kritische beschouwing heeft onderworpen. Het tegendeel is immers ook pleitbaar; coherentie van een nationale rechtsorde heeft immers een eigen waarde die steeds moet worden afgewogen tegen de waarde van harmonisering. ${ }^{20}$ Ook weegt Diamant niet de merites van de dogmatische consequenties die de implementatie van de Collateral Richtlijn heeft meegebracht, en die neerkomen op een bijzonder (goederenrechtelijk) regime voor financiëlezekerheidsarrangementen. Hevig is echter gedebatteerd over de vraag of een bijzonder regime voor financiëlezekerheidsarrangementen met ruimere bevoegdheden voor zekerheidsnemers wel gerechtvaardigd is. ${ }^{21}$ Als Diamant de hierboven in paragraaf 2 beschreven ontwikkelingen en deze vraagstukken ook zou hebben betrokken in haar onderzoek, zou dat haar proefschrift in een breder verband hebben geplaatst en het belang ervan nog groter hebben gemaakt. Dat neemt niet weg dat het een uitstekend boek is, dat blijk geeft van een grote mate van inzicht en een diep begrip van de vier (!) verschillende rechtsstelsels die het behandelt.

\section{De Collateral Richtlijn en haar implementatie}

$\mathrm{Na}$ een kort inleidend hoofdstuk van hoofdzakelijk methodologische aard worden in hoofdstuk 2 de girale activa (geld en effecten) geïntroduceerd die aan een crediteur tot zekerheid worden verstrekt in het kader van financiëlezekerheidsarrangementen. Dit onderpand, in de praktijk aangeduid als collate$\mathrm{ral}$, is 'giraal' omdat het wordt gecrediteerd op een (geld- of effecten)rekening. Vervolgens komen (de totstandkoming en inhoud van) die financiëlezekerheidsarrangementen zelf aan bod en wordt uitgelegd hoe financiëlezekerheidsarrangementen over het algemeen worden gegoten in de vorm van standaardovereenkomsten zoals die zijn opgesteld door belangenorganisaties.

Zo wordt voor repos meestal de General Master Repurchase Agreement gebruikt, op grond waarvan de debiteur in ruil voor krediet effecten tot zekerheid aan zijn crediteur overdraagt. $\mathrm{Na}$ ommekomst van de overeengekomen termijn dient de debiteur het krediet terug te betalen en de crediteur de effecten terug te leveren. Securities lending-overeenkomsten vormen in zekere zin het spiegelbeeld van repos, nu daarin de debiteur effecten 'leent' - dat wil zeggen: overgedragen

20. M. Haentjens, Harmonisation of Securities Law, Custody and Transfer of Securities in European Private Law (diss. Amsterdam UvA), Alphen aan den Rijn: Kluwer Law International 2007, p. 295-297.

21. Zie bijv. E. Perotti, Systemic Liquidity Risk and Bankruptcy Exceptions, Centre for Economic Policy Research, Policy Insight No. 52, 2010, D. Duffie \& D. Skeel, A Dialogue on the Costs and Benefits of Automatic Stays for Derivatives and Repurchase Agreements Rock Center for Corporate Governance at Stanford University, Working Paper No. 108, 2012 en R. Mokal, Liquidity, Systemic Risk, and the Bankruptcy Treatment of Financial Contracts, Brooklyn Journal of Corporate, Financial and Commercial Law 2015, afl. 10. krijgt - en onderpand (meestal in de vorm van geld of andere effecten) aan zijn crediteur overdraagt of daarop een beperkt zekerheidsrecht vestigt. De standaardovereenkomst hier heet General Master Securities Lending Agreement. Voor derivaten wordt het zekerheidsarrangement in de vorm van de ISDA Credit Support Annex gegoten en ook op grond hiervan dient onderpand in de vorm van geld of effecten aan de crediteur te worden overgedragen of daarop een zekerheidsrecht te worden gevestigd.

Alle zojuist genoemde standaardovereenkomsten voorzien erin dat bij verzuim van een van beide partijen de andere partij alle uitstaande verplichtingen kan salderen met de uitstaande schulden. De verplichting tot teruglevering van onderpand wordt daartoe 'omgezet' in een terugbetalingsverplichting ter grootte van de waarde van het onderpand, zodat de verplichtingen van beide partijen kunnen worden verrekend. De standaardovereenkomsten worden standaard beheerst door het recht van de staat New York of door Engels recht.

Hoofdstuk 3 zet de totstandkoming van de Europese Collateral Richtlijn uiteen en geeft een overzicht van de inhoud ervan. Het legt uit hoe de richtlijn voortbouwt op de zogeheten Finaliteitsrichtlijn ${ }^{22}$ en hoe de (Europese) wetgever met de Collateral Richtlijn beoogde administratieve lasten weg te nemen en rechtszekerheid te bevorderen. Zo bepaalt de richtlijn onder andere dat het bestaan, de geldigheid, derdenwerking, afdwingbaarheid noch toelaatbaarheid als bewijs van financiëlezekerheidsarrangementen mag afhangen van enige formaliteit (formaliteitenverbod). Voorts bepaalt de richtlijn dat, kort gezegd, voor de vestiging van een zekerheidsrecht (in ruime zin, dus betrekking hebbende op zowel overdracht tot zekerheid als beperkte zekerheidsrechten) slechts 'controle' mag zijn vereist (controlevereiste). Ten derde schrijft de richtlijn voor dat de zekerheidsnemer de bevoegdheid zou moeten hebben het onderpand 'te gebruiken en te vervreemden alsof hij daarvan eigenaar of gerechtigde is', ook in geval van een beperkt zekerheidsrecht (gebruiksrecht). Ten slotte wordt bepaald dat een overdracht tot zekerheid van girale activa rechtsgevolg moet kunnen hebben. ${ }^{23}$

De hoofdstukken $4 \mathrm{t} / \mathrm{m} 8$ vormen de kern van het proefschrift. Hoofdstuk 4 zet uiteen hoe de reikwijdte van de richtlijn verschillend is geïmplementeerd in de vier onderzochte rechtsstelsels. Met name is daarbij van belang het personele toepassingsbereik van de richtlijn; haar bepalingen gelden niet voor natuurlijke personen/consumenten, maar lidstaten mogen kiezen of een van beide partijen een persoon anders dan, kort gezegd, een financiële instelling (in ruime $\operatorname{zin}^{24}$ ) kan

22. Richtlijn 98/26/EG van het Europees Parlement en de Raad van 19 mei 1998 betreffende het definitieve karakter van de afwikkeling van betalingen en effectentransacties in betalings- en afwikkelingssystemen, PbEG 1998, L 166/45.

23. Andere bepalingen van de richtlijn, waaronder een verwijzingsregel van internationaal privaatrecht, bespreekt Diamant wel in dit hoofdstuk, maar komen in de rest van het proefschrift nauwelijks aan bod (maar zie par. 5).

24. D.w.z. niet in de (beperktere) zin van art. 1:1 Wft. 
zijn. Dit is een zeer controversieel punt gebleken in de Nederlandse implementatiewetsgeschiedenis en uiteindelijk is in Nederland niet van de mogelijkheid tot ruimere toepassing gebruik gemaakt. Naar Nederlands recht dient dan ook ten minste een van beide partijen een financiële instelling te zijn. ${ }^{25}$ Anderzijds kan de partij, niet zijnde de financiële instelling, ook een kleine of middelgrote onderneming zijn.

De voor- en nadelen van een ruime toepassing worden enigszins verspreid over het hoofdstuk besproken. Enerzijds betoogt Diamant dat de richtlijn zelf niet eraan in de weg zou staan de implementatiewetgeving ook van toepassing te doen zijn op consumenten en tussen ondernemingen onderling (niet zijnde financiële instellingen in ruime zin). ${ }^{26}$ Anderzijds stelt Diamant dat met een ruim toepassingsbereik systeemrisico niet wordt verminderd en dat ook de integratie en efficiëntie van de financiële markten daarmee niet worden bevorderd, ${ }^{27}$ en betrekt zij de stelling dat de reikwijdte beperkt zou hebben kunnen blijven tot financiële instellingen en grote ondernemingen. ${ }^{28} \mathrm{Zij}$ lijkt daarbij echter te miskennen dat ook kleine(re) ondernemingen (niet zijnde financiële instellingen) een financieringsvoordeel zouden kunnen genieten door, bijvoorbeeld, een repo aan te gaan. ${ }^{29}$ De door de debiteur te betalen repo rate is immers over het algemeen lager dan de rente op een gewone banklening.

In de hoofdstukken $5 \mathrm{t} / \mathrm{m} 8$ worden drie kernelementen van de Collateral Richtlijn en hun implementatie aan nader onderzoek onderworpen. Zo komen achtereenvolgens aan de orde het hierboven reeds genoemde formaliteitenverbod, het controlevereiste, het gebruiksrecht en de overdracht tot zekerheid van girale activa.

Ten behoeve van haar bespreking van het formaliteitenverbod bespreekt Diamant in hoofdstuk 5 eerst de wijzen waarop zekerheid op girale activa diende te worden gevestigd naar Belgisch, Duits, Nederlands en Engels recht vóór implementatie van de Collateral Richtlijn. Daarbij valt op dat het Engelse recht afwijkt van de andere onderzochte jurisdicties wat betreft de vestiging van een beperkt zekerheidsrecht. Anders dan voor de vestiging van een pandrecht naar Nederlands, Belgisch en Duits recht kan naar Engels recht namelijk registratie in een openbaar register zijn vereist voor de vestiging van een beperkt zekerheidsrecht op effecten. ${ }^{30}$ Voor de overdracht tot zekerheid van geld en effecten kan in alle onderzochte jurisdicties worden volstaan met een overboeking. Diamant laat dan ook overtuigend zien dat implementatie van het formaliteitenverbod van de Collateral Richtlijn slechts gevolgen had voor

25. Art. 7:52 lid $1 \mathrm{BW}$.

26. Diamant 2014, p. 67.

27. Diamant 2014, p. 76. Die stelling wordt niet nader onderbouwd, maar Diamant sluit zich op dat punt kennelijk aan bij andere schrijvers die zij aanhaalt op p. 59-61.

28. Diamant 2014, p. 58-60, 63 en 76

29. Diamant 2014, p. 60

30. Te weten: voor zover een mortgage of charge kwalificeert als een charge on book debt of als sprake is van een floating charge. Diamant 2014, p. 96-97 en 106.
Engels recht, omdat financiëlezekerheidsarrangementen daar van het registratievereiste moesten worden uitgezonderd. ${ }^{31}$

Hoofdstuk 6 behandelt het 'controlevereiste' dat de Collateral Richtlijn stelt en maakt daarbij een uitstap naar het Amerikaanse recht. Volgens de richtlijn moeten girale activa namelijk als zekerheid zijn 'verschaft', dat wil zeggen: 'in het bezit of onder de controle komen van de zekerheidsnemer'. Het belangrijkste vraagstuk dat zich hierbij voordoet, betreft het beperkte zekerheidsrecht en heeft betrekking op de reikwijdte van het begrip 'bezit of controle'. Betekent het dat de zekerheidsgever nog mag beschikken over de tot zekerheid verschafte goederen totdat de zekerheidsgerechtigde tot uitwinning overgaat (ruime interpretatie)? Of zou dergelijke beschikking reeds zijn uitgesloten vanaf het moment van vestiging van het zekerheidsrecht (strikte interpretatie)? Voor die eerste, ruime interpretatie zou pleiten dat de zekerheidsgerechtigde steeds de mogelijkheid houdt bij uitsluiting van de zekerheidsgever te beschikken.

Nederlands en Engels recht volgen de strikte interpretatie, Belgisch recht de ruime. Diamant stelt vast dat de tekst van de richtlijn zelf geen uitsluitsel biedt en gaat daarom in een analyse van richtlijnconforme interpretatie na wat het doel van het controlevereiste is. $\mathrm{Zij}$ onderscheidt de verificatiefunctie (controle zou crediteuren van de zekerheidsgever moeten beschermen tegen antedatering) en de zekerheidsfunctie (controle zou moeten voorkomen dat de zekerheidsnemer onderverzekerd raakt), maar publiciteit wijst ze - naar mijn idee terecht af als doel van het controlevereiste. ${ }^{32}$ Niet helemaal duidelijk wordt of Diamant zelf de voorkeur geeft aan de strikte of de ruime interpretatie, maar zij adviseert uiteindelijk heel praktisch om van de strikte interpretatie uit te gaan. ${ }^{33}$

Hoofdstuk 7 is een van de beste hoofdstukken van deze dissertatie en het betreft het gebruiksrecht dat volgens de Collateral Richtlijn een crediteur moet kunnen worden toegekend, (ook) als hij een beperkt zekerheidsrecht heeft verkregen. Op grond van de Collateral Richtlijn is een zekerheidsgerechtigde bevoegd te beschikken over het onderpand 'alsof hij daarvan eigenaar of gerechtigde is' en het zich zelfs toe te eigenen in geval van een executiegrond. Diamant maakt inzichtelijk hoe dit gebruiksrecht zijn oorsprong vindt in de financiële praktijk naar Amerikaans recht. Vóór implementatie van de Collateral Richtlijn was het volgens Diamant niet mogelijk een dergelijk gebruiksrecht overeen te komen naar Nederlands recht, en twijfelachtig voor Belgisch, Duits en Engels recht.

Met de introductie van het gebruiksrecht heeft de Collateral Richtlijn dan ook voor alle onderzochte jurisdicties een belangrijke noviteit geïntroduceerd, die overigens niet op eenvormige wijze is geimplementeerd. Niet duidelijk is namelijk hoe de Collateral Richtlijn op dit punt moet worden begrepen, terwijl noch de tekst, noch richtlijnconforme interpretatie uitkomst biedt. Diamant laat echter overtuigend zien dat

31. Diamant 2014, p. 104-106.

32. Diamant 2014, p. 140-141.

33. Diamant 2014, p. 151. 


\section{Maandblad}

de zekerheidsgever bij de uitoefening van het gebruiksrecht door de zekerheidsnemer zijn gerechtigdheid tot het onderpand verliest. Hij verkrijgt in ruil daarvoor slechts een verbintenisrechtelijke aanspraak op overdracht van aan het oorspronkelijke onderpand gelijkwaardige goederen. Deze interpretatie baseert zij op de Amerikaanse praktijk, waarop de regeling van de Collateral Richtlijn was gebaseerd. Daarmee komt Diamant lovenswaardig terug op het eerder door haar ingenomen standpunt dat het gebruiksrecht ook tot gevolg zou kunnen hebben dat de oorspronkelijke pandgever rechthebbende blijft van het onderpand, ook als de pandhouder het onderpand heeft herverpand. ${ }^{34}$

Hoofdstuk 8 betreft een onderwerp dat het Nederlandse rechtsleven (ten minste) sinds het Bierbrouwerij-arrest ${ }^{35}$ heeft beziggehouden, te weten: de overdracht tot zekerheid. Op grond van de Collateral Richtlijn dienen de lidstaten aan een dergelijke overdracht in het kader van financiëlezekerheidsarrangementen rechtsgevolg toe te kennen. Diamant bespreekt hoe deze bepaling tot stand is gebracht om het risico van recharacterisation - dat wil zeggen: de herkwalificatie (door een rechter) van een overdracht tot zekerheid als een beperkt zekerheidsrecht - te minimaliseren. De bepaling noopte echter ook tot aanpassing van het recht in die jurisdicties waar recharacterisation zich niet voordoet, maar waar de overdracht tot zekerheid niet of slechts beperkt wordt erkend. Nederland (maar niet Duitsland en Engeland) is een dergelijke jurisdictie blijkens het 'fiduciaverbod' van art. 3:84 lid 3 BW.

Met vreugde las ik hoe Diamant nog weer eens overtuigend uiteenzet dat financiëlezekerheidsarrangementen ook zonder de Collateral Richtlijn van het fiduciaverbod niets te vrezen hadden. ${ }^{36}$ Ten eerste maakt de volledige bevoegdheid van de zekerheidsnemer in financiëlezekerheidsarrangementen om te beschikken over het hem overgedragen onderpand dat hier sprake is van een 'werkelijke overdracht' (en niet van een overdracht zonder rechtsgevolg) als bedoeld in het Sogeleasearrest. ${ }^{37}$ Ten tweede kwalificeert noch de girale overboeking van geld, noch die van effecten als een overdracht in de zin van art. 3:84 BW, zodat ook om die reden art. 3:84 lid 3 BW niet aan de orde is. Hoe dat ook zij, art. 7:55 BW stelt thans buiten twijfel dat 'een overdracht ter nakoming van een financiëlezekerheidsovereenkomst tot overdracht geen overdracht [is] tot zekerheid (...) in de zin van artikel 84 lid 3 van Boek 3'.

Volgens Diamant is met art. 7:55 BW ook een fiduciaire overdracht tot zekerheid - dat wil zeggen: een overdracht tot zekerheid die geen 'werkelijke overdracht' in de zin van het Sogelease-arrest is - gevrijwaard van het fiduciaverbod waar het financiëlezekerheidsarrangementen betreft. De Collateral Richtlijn zelf geeft geen duidelijkheid of zij inderdaad ook dat soort overdrachten heeft bedoeld te sanctioneren, maar ik ben het graag met Diamant eens dat de financiëlezekerheidsarran-

\footnotetext{
34. Diamant 2014, p. 188.

35. HR 25 januari 1925, NJ 1929, p. 616-621 (Bierbrouwerij).

36. Diamant 2014, p. 216-218.

37. HR 19 mei 1995, NJ 1996/119 (Sogelease).
}

gementen die de richtlijn beoogt te faciliteren ${ }^{38}$ een 'werkelijke overdracht' betreffen (en geen fiduciaire overdracht). Deze vraag lijkt mij daarom van beperkt belang.

Het proefschrift sluit af met een uitgebreide 'Slotbeschouwing', waarin drie stellingen worden betrokken. Met deze stellingen kan men het moeilijk oneens zijn: 'De Collateral Richtlijn sluit aan op het door de financiële praktijk tot stand gebrachte juridische kader voor zekerheid op girale activa', 'Het is van belang te erkennen dat de (geconcipieerde) problemen waarvoor de Collateral Richtlijn een oplossing biedt, een Anglo-Amerikaanse achtergrond hebben' en 'Het is van belang te erkennen dat door de Collateral Richtlijn nieuw geïntroduceerde concepten van Anglo-Amerikaanse herkomst zijn.' Wat mij betreft vrij brave stellingen, die geen weerspiegeling vormen van de ferme en overtuigende betoogtrant die het boek elders tentoonspreidt.

\section{Conclusie: onderscheid tussen overdracht tot} zekerheid en beperkt zekerheidsrecht (pandrecht) In het laatste hoofdstuk komt Diamant (ook) tot de conclusie dat het onderscheid tussen de overdracht tot zekerheid en het beperkt zekerheidsrecht (pandrecht) door de Collateral Richtlijn en de praktijk die deze richtlijn tracht te faciliteren, is vervaagd. Door de introductie van het gebruiksrecht wordt de beperkt zekerheidsgerechtigde in gelijke mate als de eigenaar beschikkingsbevoegd. De bevoegdheid van de beperkt zekerheidsgerechtigde de tot zekerheid verschafte goederen bij verzuim toe te eigenen draagt daaraan bij. Diamant bepleit dan ook om tot één vorm van zekerheid te komen, die slechts geldt voor 'girale activa' (geld en effecten) en die tot stand komt door 'bezit of controle'. 39

Diamants laatste stelling dat voor beide typen goederen - dat wil zeggen: giraal geld en effecten - dezelfde internationaal privaatrechtelijke verwijzingsregel zou moeten gelden, kan ik volmondig onderschrijven. ${ }^{40}$ Diamant laat daarbij de keuze open of dat de huidige regel zou moeten zijn die voor girale effecten geldt (vergelijk art. 10:141 BW) of 'het recht dat de overeenkomst beheerst'. Ik heb een sterke voorkeur voor de mogelijkheid van een rechtskeuze, ${ }^{41}$ maar ik betwijfel of deze zou moeten worden vervat in de overeenkomst tussen zekerheidsgever en zekerheidsnemer. In dat geval zouden namelijk verschillende effecten, hoewel gecrediteerd op dezelfde effectenrekening, kunnen worden beheerst door verschillende goederenrechtelijke regimes. Bijvoorbeeld met het oog op een mogelijk faillissement van de financiële onderneming die de effectenrekening beheert, lijkt me meer het recht voor de hand te liggen dat van toepassing is op de (gehele) geld- of effectenrekening, welk recht door de overeenkomst tussen rekening-

38. Zie par. 1

39. Diamant 2014, p. 249-250.

40. Diamant 2014, p. 250. Evenzo heb ik eerder verdedigd, zij het op andere gronden. Zie Haentjens 2014, p. 25.

41. Zie - uitgebreider - Haentjens 2007, p. 287-292; 2014, p. 21-25. 
houder en financiële onderneming zou moeten kunnen worden bepaald.

\section{Slot}

Het proefschrift van Diamant kent een glasheldere opbouw, heeft een aangename omvang en is heel prettig leesbaar. Gezien het complexe onderwerp is dat reeds een groot compliment waard. Maar ook overigens is dit een prachtig boek, dat een grote rijkdom aan onderwerpen behandelt zonder ergens aan de oppervlakte te blijven. Zo worden voor de financiële en monetaire praktijk uiterst belangwekkende overeenkomsten aan een onderzoek onderworpen, worden zowel het Nederlandse als het Duitse, Engelse en Belgische vermogensrecht vakkundig ontleed en wordt ook het Amerikaanse recht noch het internationaal privaatrecht geschuwd. De stellingen die Diamant inneemt, zijn over het algemeen overtuigend. Het proefschrift blijft strikt binnen de gestelde hoofdvraag en dat is deels de kracht ervan. Helaas is het ook een zwakte, omdat de hoofdvraag wat mij betreft te eng is geformuleerd, zeker gelet op de wereldwijde financiële crisis die door het faillissement van Lehman Brothers werd ingeluid, en de huidige ontwikkelingen op dit front. Dat doet er echter niets aan af dat iedere serieuze beoefenaar van het vermogensrecht dit boek tot zich zou moeten nemen, om daar groot genoegen aan te beleven. 